ESGRITURA E IMAGEN

Dpto. de Filosofía IV

Despacho A-336

Tel.: $91394.5^{3} 80$

UNIVERSIDAD COMPLUTENSE
MADRID

aleyra@filos.ucm.es

FACULTAD DE FilosofÍA

La Revista Escritura e Imagen, siguiendo las directrices marcadas por los comités internacionales de ética editorial, y las normas de buenas prácticas en la publicación científica, sólo admite artículos originales e inéditos, pidiendo a los autores su compromiso, por escrito, de aceptación de dichas normas.

El equipo editorial de la Revista ha decidido proceder a la retractación formal del siguiente trabajo: "Derrida, Freud y el retorno del archivo", firmado por Rubén Carmine Fasolino y publicado en el número 11 (2015).

La razón de ello estriba en que dicho trabajo había aparecido anteriormente en otra publicación.

En Madrid, a 9 de octubre de 2017.

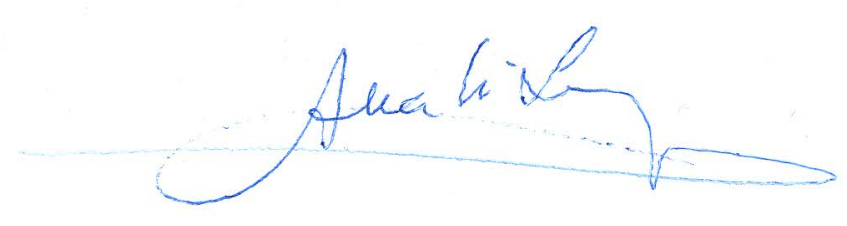

Fdo: Ana María LeYra SORIANo

Directora de Escritura e Imagen 


\title{
Derrida, Freud y el retorno del archivo
}

\section{Derrida, Freud and the return of the archive}

\author{
RubÉn CARMine FASOLINO \\ Universidad Complutense de Madrid \\ rubencfa@ucm.es
}

Recibido: 12-01-2014

Aceptado: 19-01-2015

\section{Resumen}

El artículo trata de situarse en una zonấ delıada, la del a chiv y sus males tal y como nos fueron legados por la obra de reud. Nuestra te cion será la de ponernos a la escucha de la impresión freu dian ayudados p r las eflexiones de Derrida recogidas en su obra Mal de Arcŕvo. La fórmula «e re referencia a dicha obra y a la experiencia del registr o r romovida por Freud bajo la palabra Verdrängung, epre ión que ef nposible desligar de su retorno. Encaminándonos hacia as encxiones de De rid y Freud, trataremos de esbozar la problemática del arch vo sus males, d as condiciones de posibilidad y su estamento inquietznte para ras cuestiones el erigen, la verdad y el testimonio.

Palabrc ave archivo, r p sion, retorno, transferencia, suplemento.

\section{Abstr: $c^{+}$}

This essay is oc ter in a sensitive area, the file and its fever as we were bequeathed b, th amork's Freud. Our intention will be to get listen the Freudian impression aidea by Derrida's reflections collected in his book Archive Fever. The phrase "the return of archive" is a reference to that work and record's experience promoted by Freud under the word Verdrängung: repression is impossible to separate by his return. Heading into the thoughts of Freud and Derrida, try to outline the problems of archive and its problems, its conditions of possibility and the unsettling questions of origin, truth and testimony.

Keywords: archive, suppression, return, transference, supplement. 
Algunas palabras sobre las cuestiones del archivo, de sus males y sus retornos, de su lógica de la inscripción y de sus retoños, se imponen en una época donde la posibilidad del archivo se extiende más allá de sus pretendidos límites materiales -pensemos en los servicios clouds, una tecnología que permite conectarse a los archivos en cualquier lugar y momento, siempre que se disponga de la prótesis adecuada-. Una época, entonces, amparada por la anticipación calculatoria de la tecnología que asume, a veces, el semblante de una angustiosa quietud acelerada. Una época, en fin, donde incluso el concepto de archivo parece revelado como hic et nunc siempre disponible para el cual ya no es menester reflexionar sobre las cuestiones que atañen la consignación completa del mismo, p ro que ho impide al Gespenst de Freud seguir revoloteando para recordarnos -as co no en su Viena fin de siècle- que si se habla nuevamente de registro y huel' a a partir de un cierto malestar del que él supo captar esas ramificaciones un utaron marginadas por los diagnósticos de su época, hasta las más insospechạ s vor su aparente opacidad. ¿Pero en qué medida se habla de ello? En la medi la o uesta a tod d'scurso hegemónico y estructurado bajo el patronazgo del 1 ad $\operatorname{logos}^{1}$, el diso rs a de no admite fisuras en nombre de una razón univer l, bo oigracia la azón que sustenta la lógica del capitalismo que empuja hacia un rogreso on loplenitud asume el semblante de un imperativo al goce $r$ aquillando el finta ma que sustenta dicha lógica: la negación de lo imposible C con veremos nu la constitución del archivo como su consignación, son impo ibles y el afán uese registra hoy en la dirección de una apropiación de os a chivos así ca no de su dominio, son un claro síntoma de malestar: el empu. e nnpulsivo al egis o de todo acontecimiento esconde una enfermedad de la emoria que bor a touo pasado como herencia y An-denken, pensamiento- nemuci o remem or.

Fue Freud equal oue, con inu itada luerza, mostró que los caminos por donde aparece lo in nd ional del su o. on los asignados al discurso de una conciencia segura le su propia presen la y voz, sino de aquellos surcos que recorren el cuerp 0 - emergencit a neala voz, los documentos de archivo que se revelan con efe to de retardo sin posibilidad de una domesticación anticipada. El detalle que guio a Freu ra el sic banálisis -lo mismo podemos decir de la deconstrucciónes el que parc e e monar a los designios del autor y permanecer en una cierta opacidad respecto a intención de su predicación. En ese punto, en ese momento, se identifica un ça parle, un ça se déconstruit, un mal de archivo.

De una conferencia pronunciada en 1994 en la casa-museo de los Freud en Londres, surgió un magnífico texto que nos fue legado como Mal de archivo. Una impresión freudiana. Derrida expone unas "tesis" y tantea los posibles males del

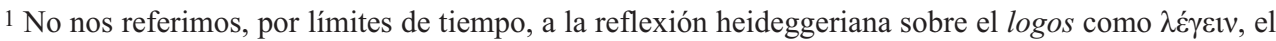
poner o disponer ante sí, sino a la conceptualización de logos como proceder de la ratio hacia una razón suficiente para sí y hegemónica, en definitiva una ratio regidora del mundo.
} 
archivo a partir del primero y más corrosivo de ellos: el hecho de que no tenemos siquiera -contrariamente a la euforia contemporánea- un concepto para lo que pretendemos asociar con la palabra "archivo". La falta tética del archivo es uno de sus males, sin duda el más radical porque, contrariamente a las apariencias, sólo disponemos para el archivo de una noción vaga de la cual nos queda a penas una impresión claudicante, la de Freud, la de Derrida, la nuestra. Parecería -desde esta "impresión"- que el impedimento hacia una constatación certera del archivo se inscribiría en el problema de la verdad como adaequatio.

Entonces deux mots sur l'archive, como dos son las veces aue dicha palabra aparece en la obra de Freud como metáfora de aquello que e gr arda lo y exhumado. Pero el psicoanálisis y la deconstrucción nos han puesto e $1 \mathrm{~g}$ arua acerca de las dislocaciones de un término, así como frente a las ausencio du wismo. Que la palabra "archivo" -su metáfora- aparezca contadas veces en a a stensa obra de Freud, no indica una ausencia de la temática, todo lo contramio. Fréud tratará siempre y sólo de los problemas ligados a la impresión de la huc la y a su perdur acy todo ello acarrea para el sujeto-. Se tratará sie np c de la cuestión de onchivo, de su consignación y de su recuperación a través de lCetividad rec olectora de la memo-

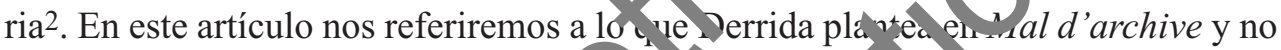
en otros textos donde la atención en redd o su teoría d la unella (Spur) es tematizada. Por supuesto habrá que ten r en cuenta lo qy Durida trató en Freud et la scène de l'écriture a propósito del sayage (el abrr e-paso que traduce el alemán Bahnung) ${ }^{3}$. Como es ampli me te conocido. ste texto que "inaugura" la relación entre Derrida y Freud se a nt principalmer te e dos textos: el Proyecto de psicología (1950 [1895]) y No q sobre la "I Iz rra mágica" (1925 [1924]). Si bien se trata de dos textos epar..os por casi. "in anos y cuyas economías textuales difieren mucho - el prin erc es un texto inacavado y el segundo quiere ser un breve resumen explica r o como Frey cen día el aparato psíquico-, en ninguno de los dos casos ê factơ "económ co" đe ra pulsión es tenido en cuenta. En el primer caso porqu la cictunción ent lo factores dinámicos, tópicos y económicos siquiera era tomada en cuenta parg ${ }^{3}$ ordar las pulsiones, y en el segundo caso porque el objeto

\footnotetext{
2 La palabra "arch v (Archive) como metáfora de lo que luego será lo "reprimido" (verdrängt) apareció/aparece una ve en los ya mentados Estudios sobre la histeria, cf. Freud S., Obras completas vol. II, trad. José L. Etcheverry, Buenos Aires, Amorrortu editores, 1978, p. 294. Más tarde en el escrito Sobre el mecanismo psíquico de la desmemoria, cf. Freud S., Obras completas vol. III, trad. José L. Etcheverry, Buenos Aires, Amorrortu editores, 1981, p. 297. Luego la palabra «archivo» como convocación de la problemática de la represión, permanecerá ausente. Quizás no se trate tanto de una falta de archivo cuanto una falta en el archivo: en efecto ya Freud, muy tempranamente, puso entre comillas la cuestión del olvido en el «recuerdo "olvidado"» ("vergessen” Erinnerung»), cfr. ibídem., p. 278.

3 Derrida, J. «Freud et la scène de l'écriture», en Derrida J., L'écriture et la différence, Paris, Éditions du Seuil, 1967, trad. P- Peñalver, Barcelona, Anthropos, 1989, pp. 275-283.
} 
del breve artículo de 1925, con la coyuntura de un invento (el Wunderblock), sirvió a Freud para que un esquema breve y explicativo diera cuenta que el sistema que percibe las huellas no puede ser el mismo sistema que las retiene.

¿Cómo se comporta el archivo en la economía textual de Freud? ¿No es esta la pregunta que ha sostenido siempre la escucha analítica respecto de algunos significantes amos, el cómo se comportan en el discurso del sujeto? No podremos seguir todos los vericuetos del archivo en el texto de Freud, sus dislocaciones, sus mimetismos, sus resistencias, pero estaremos al acecho de algunas cuestiones, las más llamativas quizás: aquello que permite la operatividad del psicoanálisic en relación a la cuestión del archivo, lo cual nos llevará a tratar la "represión" y a "tr insferencia".

Que la impresión freudiana del archivo invada también 1 s a nonios de la represión -que no es otra cosa que su retorno- $\mathrm{y}$ de la transferen $\rightarrow$ ha reimpresión de un pasado que nunca fue presente y que es reactual raco co ro vínculo actual con la figura del terapeuta-, es más que una sospecha 동 nenester recordar que también la deconstrucción, o la reflexión que la gra ita. es deudora de aquello que marca el comienzo de la experiencia freudiana e vachträglichke $n$ esente que, lejos de darse como algo puro y sin fisura est econstituid El kufecto de retardo» es cabalmente una reconstitución quo des nantela la idè aum presente puro y sin hendiduras. También la deconstru c ${ }^{\circ}$, un proceso ae aducción (del latín tra-

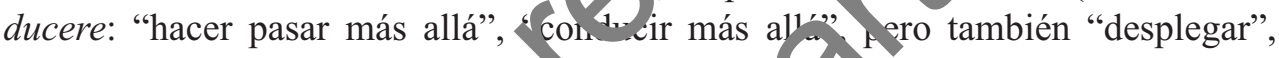
"mostrar") que habita el discurso, está referida haci lag generación misma del discurso como un "antes" que race de un "despt 's", a partir de las articulaciones del discurso ya formado y qu contantemente port consigo la ley de su propia deconstrucción, las des sea nentaciones ce io nábitan y lo contaminan y que sólo podemos reprimir para der contin ar an semblante de transmisibilidad. En resumen, las in ch cir nes que su tentany posibilitan los axiomas del corpus textual son reco. tituidas con pos rio id d aunque habiten desde siempre el discurso y lo hagan osibre.

Pr ce mos entond pre partes y empecemos por aquello que hace viable el psicoan lisis y que est' labase de la estructura neurótica: la «Verdrängung», palabra de tortuosa t $\mathrm{du}$ ( or) Derrida, en su texto ya mencionado, se percata inmediatamente de el 0 y coribe:

A diferencia de la represión (Verdrängung, refoulement, répression), que permanece inconsciente en su operación y en su resultado, la supresión (Unterdrückung, répression, suppression) opera lo que Freud llama una "segunda censura" -entre el consciente $\mathrm{y}$ el preconsciente o bien incluso afecta al afecto, es decir, aquello que jamás puede dejarse reprimir (repress) en el inconsciente, sino solo suprimir (suppress) y desplazar a otro afecto. 4

\footnotetext{
4 Derrida J., Mal d'Archive. Une impression freudienne, Paris, Galilée, 1995 (existe traducción al castellano a cargo de Paco Vidarte: Mal de archivo. Una impresión freudiana, Madrid, Trotta, 1997, p. 36).
} 
En este pasaje se subrayan diversos aspectos: por supuesto el de la traducción $\mathrm{y}$, en particular, la cuestión decisiva para el psicoanálisis que en la continuación de la conferencia, advierte el mismo Derrida, no podrá retomar y, como veremos, seguirá serpenteando por el texto de Mal d'archive. Se trata de aquello que está ligado y referido al "afecto" en la práctica psicoanalítica y que desbroza, podríamos decir, un ejercicio cuasi fenomenológico en el momento en que Freud lleva a cabo una distinción fundamental entre el afecto y el contenido de la representación adherido a él 5 . ¿Cómo concebir que un contenido pueda ser retocado sin que la exteriorización del afecto correspondiente se altere? ¿No estaríamos hablando de una contradicción? ¿Es posible identificar en esta distinción un m ler el archivo? Intentaremos una aclaración empezando por recordar que e te varente sinsentido recorre también -además de las cuestiones del archivo n nue está profundamente entrelazado- toda la obra de Freud, asomand su re encia desde los escritos más tempranos. En concreto podemos leer la sigü nte aclaración en Las neuropsicosis de defensa, obra del año 1894:

La conversión puede ser total o parcial y obr ve hádrá en aqu la ine vación motriz o sensorial que mantenga un nexo, más ím. no más laxo, son a vir ncia traumática. El yo ha conseguido así quedar exento đe on udidicción, pe o, cambio, ha echado sobre sí el lastre de un símbolo mnémic q h oita la concien a al modo de un parásito, sea como una inervación motriz irreso uble o como un sen acrón alucinatoria que de continuo retorna, y que permarará ahí hasta que sobre ga una conversión en la dirección inversa. En tales on licio les, la huella $1 \mathrm{~m}$ émica de la representación reprimida \{esforzada al desalojo on ha sido sepultada un ergeben\}, sino que forma en lo sucesivo el núcleo de un gru $p$ psíquico seg $\ln _{4} \mathrm{O}^{\circ}$

Siendo esqu mo ti os, podemo afirmar que el aparato psíquico, para escabullirse de una répenación inco ac iave, tiene varias posibilidades: las más conocidas sen la th sposición a lo son ático o el desplazamiento mediante un enlace falso

\footnotetext{
5 Muy bruvemente resun ir my la etiología de las neurosis en su formulación esencial -y cuando todavía no se ten an el cue los factores dinámicos, tópicos y económicos ni, por supuesto la compulsión a la repet ió 1 - una siguiente manera: frente a una representación inconciliable (unverträglichen Vorstellung) qu no puede ser abreaccionada -descargada y "metabolizada"-, el yo (la "agencia represora") aplica una censura (Abwehr) cuyo fin es la defensa (Widerstand): se emprende así una separación entre el contenido de representación y su afecto mediante una conversión a una parte del cuerpo - en el caso de la histeria-, una trasposición mediante un enlace falso a otra representación psíquica -en el caso de una neurosis obsesiva-, o el desplazamiento del afecto hacia un objeto sustitutivo -en el caso de la fobia-. Lo que se reprime (verdrängt) es la representación inconciliable correspondiente al trauma, pero no el afecto: éste, al ser desplazado (verschieben), sigue operativo y modula los retornos que asumen la formación de síntomas somáticos, insistencias obsesivas y fobias, todas estas reconocidas como "formaciones de compromiso".
}

${ }^{6}$ Freud 1978, op. cit. (nota 2), p. 51. 
a otras representaciones. Todo ello es posible porque, mediante la censura (Abwher), se ha operado un divorcio entre el contenido de representación y el monto de afecto (Affektbeträg) adherido a ella -lo cual muestra como el síntoma es una formación de compromiso, un gasto sin duda, pero que sigue siendo menor para el organismo porque le permite al sujeto "rodear" la cuestión concerniente su deseo-7.

El "divorcio", a lo largo de la teoría freudiana, es obra de la "agencia represora", del "yo" y, finalmente, de la angustia. Sería sin duda interesante adentrarnos en la evolución de la formación de síntoma en Freud, pero dicho camino sugestivo nos llevaría por derroteros lejanos al presente artículo. Sin en har o t ndremos que adentrarnos en una leve digresión para captar a fondo el mal de rcnlvo en relación a la Verdrängung. De hecho, con la introducción de los forto ópicos, dinámicos y económicos, el monto de afecto también puede e ${ }^{2}$ r m pletamente sofocado ${ }^{8}$. Es lo que Freud describe en Lo inconsciente (1915) a muestra que Derrida, en la cita que propusimos al principio, anduvo acertado

La cuestión que se abre paso en la meta sio logía freudian c. untonces, lo inherente al comercio entre las localidades ́síq i as, lo que ro haco más que complicar la cuestión del archivo - ¿o acaso a her amos sup cer ru-s esta nueva concepción del archivo que desestabiliz a 1 anterior apar to onceptual de Freud?-. Antes de ofrecer nuestra hipótesis, es sum do que en tex Lo inconsciente el autor aplica la distinción entre "represenuación-cosa" (s chvorstellung) y "representación-palabra" (Wortvorstell ng), afirmando qu si no nay enlace entre una y otra, es decir, que si la primera nu e obreinvestid po los enlaces de representacionespalabra correspondientes n el sistema I rC , la representación-cosa en el Icc -desligada de toda sigr ancaión- dará lus a copresión:

[...] la rer sen ción conscie a an a la representación-cosa más la correspondiente represer acion-palabra, y la $n$ or ciente es la representación-cosa sola. El sistema Icc co tron la investidu as cosa de los objetos, que son las investiduras de objeto prime o y genuinas; el sis ma Prcc nace cuando esa representación-cosa es sobreinvestida or el enlace or 12 s representaciones-palabra que le corresponden. Tales sobreinvestiduras, ode nos onjeturar, son las que producen una organización psíquica más alta y posib an errelevo del proceso primario por el proceso secundario que gobierna en el interior a Prcc. Ahora podemos formular de manera precisa eso que la represión, en las neurosis de trasferencia, rehúsa a la representación rechazada: la traducción en

\footnotetext{
7 Sobre la cuestión del deseo (Wunsch) no podremos explayarnos como sería conveniente debido a la suma importancia que dicha palabra mantiene para el psicoanálisis, en particular en Freud y Lacan. Los límites, una vez más, de tiempo y espacio nos obligan a proceder sin demasiados rodeos, esenciales y constitutivos tanto del psicoanálisis como de la deconstrucción.

8 Freud S., Obras completas vol. XIV, trad. José L. Etcheverry, Buenos Aires, Amorrortu editores, 1979, p. 174.
} 
palabras, que debieran permanecer enlazadas con el objeto. La representación no aprehendida en palabras, o el acto psíquico no sobreinvestido, se quedan entonces atrás, en el interior del Icc, como algo reprimido. ${ }^{9}$

Sobre cómo la representación de la cosa es aprehendida en palabras, habría mucho que reflexionar ${ }^{10}$, pero prosigamos y subrayemos que este pasaje se encuentra hacia el final del texto y trata de fijar, de una vez por todas, el punto de origen -no cronológico, pero sí al menos lógico-de la represión. Si lo comparamos con un pasaje al comienzo del mismo texto, vemos que un término que siempre acaparó la atención de Derrida -el de "transcripción" o "retranscripción ( 0 nschrift)- ha desaparecido:

Sí queremos tomar en serio una tópica de los actos aními of nemos que dirigir nuestro interés a una duda que en este punto asoma. Si un c to qquico (limitémonos aquí a los que son de la naturaleza de una representación expennenta la tracescición del sistema Icc al sistema Cc (o Prcc), ¿debemos mon ar que a ellâ se li a Ina fijación \{Fixierung\} nueva, a la manera de una segund $t$ as vipción de la m sentación correspondiente, la cual entonces puede cont ner tamoién en una n reva localidad psíquica subsistiendo, además, la trascripción or̂̀ nara, inconsc te , $v$ más bien debemos creer que la trasposición consiste e $\mathrm{y}_{\mathrm{A}}$ sambio de estr do to se cumple en idéntico material y en la misma localidad

Parecería que para sup rar 1 obstáculo ve representa la posibilidad de una serie de transcripciones en tro 1o localidades psí vicas - un aspecto que es a la vez tópico, dinámico y econo nivo ya que e e ata de una fijación que promueve una

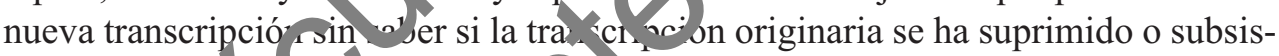
te-, Freud desbara ara a posibilida ade ciserentes transcripciones y con ello la complicación de gun todos los de tón tópicos, dinámicos y económicos, escogien-

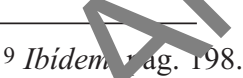

10 En par cular porque el oas je que acabamos de citar muestra en Freud una marcada importancia de la "actividad comr con ora' (Vestehen) en el ser humano, además de corroborar que la génesis de la significación es egre Sin duda, desde un planteamiento gnoseológico, habría que considerar la relación entre el $V_{e}$. tehen heideggeriano y los juicios atributivos y de existencia tal y como los trata Freud en su artículo Die Verneinung. También habría que interrogar la estrecha relación que subsiste entre la Befindlichkeit y la Übertragung. Estos aspectos no fueron dilucidados con la atención que merecen en los Seminarios de Zollikon, cf. Heidegger M., Zollikoner Seminare, Frankfurt am Main, Klostermann, 1987 (existe traducción al castellano: Seminarios de Zollikon, trad. de A. Xolocotzi Yáñez, México, Morelia editorial, 2007, p. 227-228). La cuestión de la aprehensión de la representación-cosa y su enlazamiento con la representación-palabra "correspondiente", otorgaría cierta validez al Autre lacaniano como lugar de la palabra al que estoy -como sujeto- siempre referido, a un orden simbólico que me determina y que es independiente del sujeto hablante.

11 Freud 1979, op. cit., (nota 8), pp. 169-170. 
do una opción para que la represión surja allí donde hay un impedimento en la génesis de la significación. Es menester recordar que para Freud tanto el sueño como el síntoma están estructurados según sucesión y simultaneidad de significados. El siguiente pasaje extraído del caso de Dora lo muestra de forma inequívoca:

Ya tenemos averiguado que un síntoma corresponde con toda regularidad a varios significados simultáneamente [Bedeutungen gleichzeitig]; agreguemos ahora que también puede expresar varios significados sucesivamente [Bedeutungen nacheinander]. El síntoma puede variar uno de sus significados o su significado principal en el curso de los años, o el papel rector puede pasar de un significado a otro. Hay co no in rasgo conservador en el carácter de la neurosis: el hecho de que el síntoma y co nsti uido se preserva en lo posible por más que el pensamiento inconsciente que n él expresó haya perdido significado. ${ }^{12}$

¿Acaso la simultaneidad de significados en el sitrom y su encadenamiento por sucesión no remiten a los tropos de la metáfora v m tonimia v e st s, a su vez, a los procesos de condensación y desplazamiente mo condicion cu posibilidad del sueño? En efecto, que Lacan hable dế síntuma com $\bullet$ táfô a no nos parece una violencia al texto freudiano en cuanto lecmos en va os nomentos de su obra que la formación de síntoma está ac re ida por la pe mul.ción. Freud lo mostró sobre todo en la Traumdeutung y en su Zur Psyclo atrologie des Alltagslebens, mientras Lacan lo resumió en la sigurente fórmula qu e rarafraseamos: todos los elementos que se encuentr $n$ a oci dos en la can a significante pueden verse tomados como equivalentes hs nos de los otros. Sin mbargo, tal y como sucede con el significante enigmátiôn - - que saltó de la cádena y por el cual se da la insistencia de su búsqued-, ray un érmino qué a sruo suprimido: el de transcripción. ¿Qué hay de las transi rip is hes?

Vemos uo en ra nueva co ce tuanzación de la Verdrängung como enlace fallido en la Lingvorstellung y la Wrtvorstellung, se mantiene el aspecto de la disociació, érudos elemer os. Como acabamos de anticipar, en esta concepción de la represio y se apoya a at 10 que Lacan desarrollara como l'insistance de la chaîne signifiante, esa ou qu da repetitiva del eslabón elidido, el significante que no está ligado a su si ni cucón correspondiente. De hecho cuando nos representamos al inconsciente con la memoria de lo que olvida, no se trata más que de una forma de traducir aquello que Lacan transmitió como el significante elidido, aquel que saltó de la cadena13. ¿Qué otra cosa es para Lacan el sujeto representado por un sig-

12 Freud S., Obras completas vol. VII, trad. José L. Etcheverry, Buenos Aires, Amorrortu editores, 1978, p. 46.

13 Lacan J., Le Séminaire de Jacques Lacan, Livre VII. L'Ethique de la psychanalyse, 1960-1961, Paris, Éditions du Seuil, 1980, trad. D. S. Rabinovich, Buenos Aires, Paidós, 1988, p. 270. 
nificante -y para otro significante-, sino el significante elidido como tal en cuanto sujeto? 14

Pues bien allí, en el lugar de la elisión, se gestan varios males y uno de ellos es la impenetrabilidad de algunos documentos, su poder subsistir sin la actividad normativa del yo, casi como si la acumulación de los archivos dejaran de necesitar a aquel que los acumula. Un archivo, entonces, que incluso se modifica con posterioridad sin un acto de la voluntad consciente, escapando a la regulación, un archivo, entonces, que persiste en su desalojamiento, silencioso, encriptado, que puede alzarse mediante una insistencia que se vuelve parasitaria para poder ser exhumado ${ }^{15}$. Un archivo, en fin, como huellas que subsisten sin mí c mo esto desenterrado "Es war, als ob man ein, wohl in Ordnung gehalter es, Mrchiv ausnehmen würde"16, el archivo desenterrado y devuelto a la luz a parfecto orden. Dicha impresión es la de un archivo que asume los tintes dol ( $p$ li, roso) suplemento que puede ser una suplencia -el archivo recuperado que wel na el hueco de mi mosaico consciente-, o bien un recuerdo de cobertura, un s vlei hento por añ id dura del cual no podemos saber qué, exactamente, está sus to y nono. La problo na iea subrayada por Derrida acerca de lo que llamamos ap sur damente "su lemento" es su indecidibilidad: a la vez que suple, añade y â vaz que añal's s pro. Uno de los mejores ejemplos lo da una vez más Freuc cyando relata el siso lel hombre de los lobos como mito individual del neuró $\mathrm{co}$ : unánto de a e cena que funciona como soporte de los fantasmas del sujeto o. añadidura y c án ro desfiguración? ${ }^{17}$ Las tribulaciones de Freud sobre as a ndensacione v los desplazamientos que recorren "la" escena originaria, son drons de nota: 1 ans an todos los caminos que van de una escena desfigurada a na escena ca 1 r creada por completo. Ya no es la escena, sino una esce a pos. le como lu. ar anscripciones y de diferimientos. Son aspectos en los ua es io podremo entrar, pero que nos acercan aún más al mal del archivo:

El Trc es hipomn ic Y señalemos de pasada una paradoja decisiva sobre la que no $t$ ndremos tiemp de aver, pero que sin duda condiciona todo este propósito: si no hay archivo sin co gr ición en algún lugar exterior que asegure la posibilidad de la memorizac on, e la repetición, de la reproducción o de la re-impresión, entonces, acordémonos tă sén de que la repetición misma, la lógica de la repetición, e incluso la

\footnotetext{
14 En este punto citamos las meritorias palabras de Jorge Alemán: "La hipótesis del inconsciente es un modo de concebir la captura del ser hablante por la lengua", en Alemán J., Derivas del discurso capitalista, Málaga, Miguel Gómez Ediciones, 2003, p. 23.

15 Freud 1978, op. cit. (nota 2), p. 294.

16 "Era como si se exhumara un archivo mantenido en perfecto orden", en ibídem, pp. 293-5.

17 Por límites de espacio no podemos analizar los comentarios de Freud acerca de la Urszene ("Escena primordial"). Para los interesados renviamos a De la historia de una neurosis infantil, en Freud S., Obras completas vol. XVII, trad. José L. Etcheverry, Buenos Aires, Amorrortu editores, 1979, p. 29-40.
} 
compulsión a la repetición, sigue siendo, según Freud, indisociable de la pulsión de muerte. Por tanto, de la destrucción. Consecuencia: en aquello mismo que permite y condiciona la archivación, nunca encontraremos nada más que lo que expone a la destrucción, y en verdad amenaza con la destrucción, introduciendo a priori el olvido en el corazón del monumento. En el corazón mismo del «de memoria». El archivo trabaja siempre y a priori contra sí mismo. ${ }^{18}$

¿Qué significa que el archivo trabaje contra sí mismo? El archivo, suplemento que añade y suple a la vez, memoria y posibilidad de todo acontecimiento, está habitado por un mal. Que el mal del archivo se deje vislumbrar e cexto de Freud por las metáforas que intentan atraparlo -al archivo, a su co ce to mposible- es una vía que el psicoanálisis y la deconstrucción incitan a s guil. Paso a paso nos invade las sospecha que a la cuestión del archivo está 1 ga a ouro aspecto ineludible: el de la "impresión", lo cual nos devuelve otra ' Z : 1) temática de las transcripciones que se trataron de suprimir. Derrida, en eT prewnbulo de $M a l$ de archivo, lo subraya: "La primera impresión seria escritn topográfica. la de y na inscripción (Niederschrift, dice Freud de un extrem a stn $>$ de su obra' qu deja una marca en la superficie o en el espesor de un so or "ls. Sabemos - g acils a cierto efecto de retardo desenterrado por Derrida a ve lo largo de w wra Freud abunda en metáforas ligadas a la idea de la imp ól y de la insc ncion, incluyendo palabras circunscritas al ámbito de la tipog afía, tales com " imrpresión" ("Neudruck") y "reedición" ("Neuauflage") Más allá de famco carta enviada a Fliess el 6/XII/1896, para reenco tra nos con la tem ito de la "impresión" nos basta con volver a las páginas en as que se analizanreso de la trasferencia (Übertragung) y constatar que tam sién en esta c van ica de repetición tan peculiar, el analista tiene que hab rsel is una vez mós o n reimpresiones y reediciones de vivencias psíquicas qu pa a erpaciente perr ane cen inconscientes, pero que vive "como vínculo actual con la persona d 1 dico"20. También en ese transporte de afectos corre nondic te a vivencia del $n$ sado que nunca fueron presentes, que se reiteran en la c r.ciencia como si rou, ran de la nada, pues bien, también en este transporte se trata le un mal de ar bivo, de un retorno de éste. Dicho de otra manera, el mal de archivo cor $\mathrm{O} t$ asine nia es aquel momento en que se implica un no saber por parte del sujen seconstituye un sujeto-supuesto-saber, el analista, que no tiene por qué saber $-y$ de hecho no sabe nada-21. La trasferencia es cabalmente el

18 Derrida 1995, op. cit. (nota 4), págs. 19-20.

19 Ibídem, p. 34.

20 Freud 1978, op. cit. (nota 12), pág. 101. Sin embargo, la primera vez que aparece el término "trasferencia" en el mismo sentido es en los Estudios sobre la histeria, en Freud 1978, op. cit. (nota 2), pp. 306-7.

${ }^{21}$ Hemos de aclarar que la transferencia, sin duda un mal (de) archivo, es también la única ancla de salvación para el análisis: "La trasferencia, destinada a ser el máximo escollo para el psicoanálisis, se 
encuentro de(1) otro a través del cual el sujeto puede desarrollar el inconsciente en cuanto saber desplegado como efectos de verdad, pero que se producen -tales despliegues- en unos ámbitos no controlados por el saber. En la transmisión mediante el dicho hay una parte que va más allá - el decir- cuya virtualidad opera y no es fácilmente franqueable. Esta virtualidad -en la cual el sujeto está cuestionado- no siempre se puede manejar y el escollo de la transferencia es este: el sujeto (de la enunciación) habla a través del sujeto (del enunciado) y no se reconoce como tal. En este desconocimiento está incluido el receptor, que está siempre descentrado al representar otro del que es, puesto que en la trasferencia se plasma una estructura que pone en juego (algo de) la verdad y que no tiene nada qu v r co una serie de sentimientos advertidos por el paciente. Es cabalmente una r epr ducción en la cual lo más transparente pasa completamente inadvertido: lon an bi os exhumados en tanto suplencia o añadidura. Esto nos devuelve al n al ce ar hivo como represión: nunca se reprime "algo", sino que el estatuto ontológio ac la represión es la disociación. Estas consideraciones abren -o deberían haḉrlo- un nue oscenario: el archivo y la transferencia contaminarían -a 1 o que lo posib ita el delicado ámbito del testimonio, incluso del análisis Lo cean, lo ase fian porque la trasferencia, por lo que hemos escrito hasta en nor ento, trast as a cundamento de la verdad y, por consiguiente, del testin or a al poder sex an a copia sin edición original y Derrida, por su parte, indicé en Deure. Fir teimogne como el testimonio está contaminado por una cia ta ficconalidad es ructural22. No lo dudamos, pero nos preguntamos en qre se ancla la ficci nalidad, a qué es inherente. En este punto las posturas difieren p.os si para Lac. n es siempre el orden instituido por el significante el que propic que sea la $\mathrm{m}$ sr a verdad la que haga posible la existencia misma de la fi crón 3 , para Derri. la fi cionalidad es inherente a la estructura misma y comprenc arí también lo que sudenomina "significante".

Del misto mido, tampoga nd mos afirmar tajantemente que lo que hace posible la îrdau como ficción y a contaminación mutua entre ambas, es el orden institu do $\mathrm{pr}$ el signific a to -a secas, el lenguaje- $\mathrm{y}$ todo aquello puesto en marcha desde e metáfora y pacton mia, condensación y desplazamiento. Si parece incuestionable que en os op os o procesos radica la contaminación entre verdad y ficción, su relac on adisoluble. Lacan no dejará de insistir que es bajo la égida del

convierte en su auxiliar más poderoso cuando se logra colegirla en cada caso y traducírsela al enfermo"; cf., Freud 1978, op. cit. (nota 12), pág. 103.

22 Derrida J., Passions de la litterature. Avec Jacques Derrida, Paris, Galilée, 1996, p. 23.

${ }^{23}$ Lacan J., Écrits, Paris, Éditions du Seuil, 1966 (existe traducción al castellano: Escritos, trad. de T. Segovia, Buenos Aires, Siglo XXI Editores, p. 24). Esta cuestión es difícil de resolver, pues no estamos seguros que el significante lacaniano sea el mismo que Derrida entiende y tampoco creemos que pueda resolverse en el ámbito de un significado trascendental. Por otra parte, tampoco la alteridad radical y el Autre lacaniano coinciden. Estas son algunas de las dificultades que se encuentran a la hora de escuchar el diálogo, la relación-sin relación entre Lacan y Derrida. 
Autre como lugar de la palabra que puede haber entre dos sujetos un testimonio fiable, un garante al cual remitirse no en tanto otro ente, sino en cuanto lugar de la palabra. Solo en el registro del lenguaje es posible articular un discurso sobre la verdad -aunque sea a través de la mentira- y mentir mediante la verdad, revelando, a la vez que trata de ocultarse, una contaminación entre ambas. Para ello podemos citar el famoso chiste de los dos judíos, tan amado por Freud, Lacan y Derrida:

En una estación ferroviaria de Galitzia, dos judíos se encuentran en el vagón. “¿Adónde viajas?”, pregunta uno. “A Cracovia”, es la respuesta. “¡Pero mira qué mentiroso eres! -se encoleriza el otro-. Cuando dices que viajas a Cracovia me qu eres hacer creer que viajas a Lemberg. Pero yo sé bien que realmente viajas a Crac ia. or qué mientes entonces?"24

Estos juegos que entremezclan verdad y mentira, "re citaminan tanto a la ficción como a la veracidad con su par oposicional, uizás séan anticipados y generados por el mal de archivo, su imposibilidad do ta lecerlo coñ o ple hcia o añadidura, su efecto après coup que hacen in po bb-en el re sistro simbólico, allí donde no hay borradura sin resto- la po oli dad de un retorno a $u / 1$ lugar de origen puro e incontaminado. El archivo pue à vir sin mí y nhy lo de acumulación y conservación que lo nutre están ba ra os por el mal dê archrno y su imposibilidad de un retorno a la "mismidad", po la razón de qu p. hay una vuelta sobre sí sin pérdida y que no esté alterad a su retorno a lo mi $m$ por una ingobernable alteración.

Antes de aclarar lo â en s escrito, habú ue centrarse sobre las condiciones de posibilidad de la trasfu en ra. ¿Cóm “s lae" la trasferencia? Será necesaria otra pausa, otro brषve ode (détour), pona antar mejor la importancia de este concepto fundamer l. reu aborda por rim era vez esta cuestión en el caso de Dora -un caso, por lo derás, en el que de 1 transferencia no se hizo un uso ejemplar-. Allí se ap en en pocas pi cel $d$ ds, una definición harto precisa y que no se modificará c ncrálmente en su s.ơuientes obras:

¿Qué son 1. tr: sfer mlas? Son reediciones, recreaciones de las mociones y fantasías que a medic que cr análisis avanza no pueden menos que despertarse y hacerse conscientes; pero lo característico de todo el género es la sustitución de una persona anterior por la persona del médico. Para decirlo de otro modo: toda una serie de vivencias psíquicas anteriores no es revivida como algo pasado, sino como vínculo actual con la persona del médico. Hay trasferencias de estas que no se diferencian de sus modelos en cuanto al contenido, salvo en la aludida sustitución. Son entonces, para continuar con el símil, simples reimpresiones, reediciones sin cambios (Das sind also, um in dem

24 Freud S., Obras completas vol. VIII, trad. José L. Etcheverry, Buenos Aires, Amorrortu editores, 1979, p. 108. 
Gleichnisse zu bleiben, einfache Neudrucke, unveränderte Neuauflagen). Otras proceden con más arte; han experimentado una moderación de su contenido, una sublimación, como yo lo digo, y hasta son capaces de devenir conscientes apuntalándose en alguna particularidad real de la persona del médico o de las circunstancias que lo rodean, hábilmente usada. 25

¿De quién es subalterno el médico? De los primeros objetos amorosos que, habitualmente, son los padres. Las mociones pulsionales experimentadas con los padres o con aquellos que ejercieron sus funciones, retornan en una "reimpresión" ("Neudruck") y "reedición" ("Neuauflage"), pero puede tratars ta lbién -y aquí radica el mal de archivo para el que no disponemos de un cot e to alvo el poder "llamarlo" "suplemento"- de una repetición sin edición ori rina, es decir, de una añadidura, de un sustituto del que no se sabe qué o quiér es sustituyendo: algunas mociones pulsionales que se reeditan en la actualica a co el analista, no fueron vividas como tales en su época y se apuntalan aho a, graulas a la tracrencia, aña-

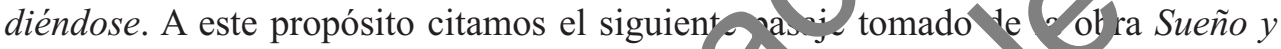
telepatía (1922) que trata el sueño recurrent de ur a mujer do a c rostro del sujeto masculino no se presenta hasta ciert mu mento: "El orioi al r unca se le había mostrado, pero su copia (Abdruck) en " "tra cerencia" al "riza la conclusión de que habría debido de ser desde siempr e oar re"26. "Habri debido ser", pero lo único que sabemos es una falta radical po la cual caemos er c na aporía: hay copia sin original. Se reeditan archivos, $\sigma$, parecen de un modo nás unheimlich, teñidos por una familiaridad que se $\mathrm{m}$ so pechosa e iqu ietante: la suposición que el archivo sea una suplencia y na ñadidura a la vo desmantela la carga angustiosa que lo indecible del ar his porta consis, s) mal radical.

Por ello volve nos a preguntarnas o on Derrida: ¿hasta qué punto podemos tratar del "cono "sto de archivo" ante y d spués de Freud? Derrida nos deja, sin duda, unas líneas de ibrante homer aj, 1 padre del psicoanálisis:

Qu 0 hablar de la imp esi n dejada por Freud, por el acontecimiento que porta este apel do, la impres on asi inolvidable e irrecusable, innegable (incluso y sobre todo por los que la n .ga ) ce sigmund Freud le habrá hecho a cualquiera que, después de él, hable de él l saú, y deba, por tanto, aceptándolo a no, sabiéndolo a no, dejarse mar-

25 Freud S., ibídem., p. 101. También Lacan en su seminario dedicado a la transferencia insiste más veces en que la realidad del pasado es la esencia de la trasferencia. Añadimos que dicho pasado se da como reproducción en el presenta y no como presencia que convoca un pasado. Cf. Lacan J., Le Séminaire de Jacques Lacan, Livre VIII. Le transfert, 1960-1961. Paris, Éditions du Seuil, 1991 (existe traducción al castellano: Seminario. Libro VIII, trad. E. Berenguer, Buenos Aires, Paidós, 2004, p. 202).

26 Freud S., Obras completas vol. XVIII, trad. José L. Etcheverry, Buenos Aires, Amorrortu editores, p. 205. La estructura de la verdad es puesta en tela de juicio por la dinámica de la trasferencia en cuanto ésta se dirige inconscientemente sobre un objeto que refleja a otro. 
car así: en su cultura, en su disciplina, sea la que sea, en particular la filosofía, la medicina, la psiquiatría y más precisamente aquí, ya que debemos hablar de memoria y de archivo, la historia de los textos y de los discursos, la historia política, la historia del derecho, la historia de las ideas o de la cultura, la historia de la religión y la religión misma, la historia de las instituciones y de las ciencias, en particular la historia de ese proyecto institucional y científico que se llama el psicoanálisis. Sin hablar de la historia de la historia, la historia de la historiografía. En cualquier disciplina que sea, ya no se puede, no se deberá ya poder nunca más - por tanto, no se tienen ya el derecho ni los medios para ello-, pretender hablar de esto sin haber sido marcados con anterioridad, de una forma o de otra, por esta impresión freudiana. Es imposible -ilegítimo hacerlo sin haber integrado, bien o mal, de forma consecuente o no, res sno iénc ola o denegándola, lo que se llama aquí la impresión freudiana. Si se tiene a li prusón de poder no tenerla en cuenta, olvidándola, borrándola, tachándola u obiatá dol , ya se ha confirmado, se podría incluso decir refrendado (por tanto, archiva do, lguna "represión" alguna "supresión" (répression o suppression). He aquí qứ á l_ a ae yo entendía sin entenderlo, lo que oscuramente quería sobre-entender pe "impresión freudi $\cdots$ ", dejándome dictar estas palabras al teléfono. ${ }^{27}$

"Dejándome dictar estas palabras a en fono", aparato pr tés co representante del ghost con el que Derrida puede entanor sin entende, - o ntender après coup, con efecto de retardo- la "impresićn "uciana", imprés ón cuspués de la cual no se podrá tratar la cuestión del archivo No de la mism a o ma, al menos. Poco importa que la impresión dejada perareud se integ bien ( nal en las andanzas contemporáneas de, por ejemph in mentados ser ic os clouds, en cuanto su impresión tiene valor retroactivo y a nodificado-daca si mpre-aquello que le pertenece al archivo, a sus males y a to bo lo problem a que lo rodea. Cualquier gesto de evitación/elusión/refi gio/-vasiva refrenda á la impresión freudiana y de nada valdrá apelar a la cistin cion de métodos 6 di ciplinas: "no se tienen ya el derecho ni los medios par en" apunta Der 10 , -aunque es cierto que el discurso capitalista y los fantas po él producid s tr. to 1 una y otra vez de suprimir ciertas impresiones "pernic ir sas...-.

Opta remos por d jarins interrogar - en contra de una razón dominante que trata de refrendar y di cuı sin fisuras- por lo que más nos asedia en Mal d'archive: aquellos mom os que unen la reflexión derridiana sobre la inscripción, el soporte y el espaciamic to, al corpus freudiano, tal y como queda reflejado claramente en este pasaje:

Freud ha hecho posible el pensamiento de un archivo propiamente dicho, de un archivo hipomnémico o técnico, del soporte o de lo subyectil (material o virtual) que, en lo que ya es un espaciamiento psíquico, no se reduce a la memoria: ni a la memoria como

27 Derrida 1995, op. cit. (nota 5), pp. 38-39. 
reserva consciente, ni a la memoria como rememoración, como acto de recordar. El archivo psíquico no corresponde ni a la mnéme ni a la anamnesis. ${ }^{28}$

Sabemos - gracias a la publicación de documentos privados- que la cuestión del archivo fue escrita y enviada por Freud a su amigo Fliess en una carta a la que ya nos referimos, la del día 6/XII/1896. No se habla de "archivo" como tal, pero sí de impresión y de lo que a ella está ligado:

[...] Tú sabes que trabajo con el supuesto de que nuestro mecanismo psíquico se ha generado por estratificación sucesiva, pues de tiempo en tiempo el mat ial preexistente de huellas mnémicas experimenta un reordenamiento sec. velos nexos, una retranscripción $\{\text { Umschrift }\}^{29}$. Lo esencialmente nuevo en n teo ía es, entonces, la tesis de que la memoria no preexiste de manera simple, in mutiple, está registrada en diversas variedades de signos [subrayado nuestro] an homento (afasia) he afirmado un reordenamiento semejante para las vías qu freg odesde la periferia [del cuerpo a la corteza cerebral]. Yo no sé cuántas de estas rasc ipciones exis er. Por lo menos tres, probablemente más. ${ }^{30}$

Se trata, en efecto, de una tesis que nu pu de decirs gu queda truncada y sin voz -afásica-, en el mismo moment e c cue inscribe los bases de su asidero en un suelo inestable y endeble que tier cono punto de a oy lo múltiple y no lo simple, impidiendo, a priori, la consignn ción hegemóni ca clara e identitaria del concepto de memoria. Tambiér la nemoria en c misma constitución, tal y como lo hace el archivo, trabaja co tra misma. La ase nuestro conocimiento, el almacenamiento recolecto de memoria, es m $m$ tiple y no simple: algo puede perderse en las diferentes tr anscr. ciones y en. "s divas variedades de signos" una dislocación podría trass ea edificio conceptual de lo tético. Hemos aquí la cuestión que se abre so o n la entrad a n ena de las transcripciones que constituyen e imposibilita a a la vez la em org no ra de un origen que no será simple, sino en diferimien to direrenciacio e tre varios registros. De manera cabal, el archivo y la memor, si bien sea as ondiciones de posibilidad de fijar una identidad, no hacen mas que tra to "to da posibilidad de "mismidad", de vuelta sobre sí, a menos que esta vuel a a mismidad no esté alterada de tal forma que introduzca en "lo mismo" (que re rna) una ingobernable alteración. Dicha alteración es el resto que

\footnotetext{
28 Ibidem, p. 99.

29 Seguimos la traducción de J. L. Etcheverry de Umschrift por retrascripción o inscripción, tal y como traduce en la edición completa de las cartas Fliess, aparecida en Norteamérica en 1985 y traducida al castellano en 1994: Freud S., Cartas a Wilhelm Fliess, trad. José L. Etcheverry, Buenos Aires, Amorrortu editores, 1994, p. 218. Apuntamos que se podría traducir por "reescritura" o "sobre (Um)escritura (schrift)".

30 Freud S., Obras completas vol. I, trad. José L. Etcheverry, Buenos Aires, Amorrortu editores, 1982, p. 274.
} 
en todo decir va más allá de lo dicho, esa parte de la voz no inscrita en el grama $(\gamma \rho \alpha ́ \mu \mu \alpha)$ y que no encuentra morada al estar en la diferencia entre lo ya no natural y lo no todavía discurso significante ${ }^{31}$. Pese a esta clarividencia que encontraba su anuncio en las afasias y en los síntomas de conversión histérica, es bien sabido el optimismo que acompañaba el comienzo de las especulaciones freudianas y que se ilusionaba con la posibilidad de volver a encauzar y acoplar la representación reprimida con el afecto desplazado. En aquellos años dorados de las andanzas freudianas, con el retorno de lo reprimido se suponía la curación: la representación inconciliable puede ser nuevamente significada y con ella, a posteriori el afecto desplazado puede dejar de ocupar el lugar parasitario en el interit r e lo anímico para encontrar su justo alojamiento y dejar de insistir en la ca ien significante para poder ser simbolizado. Sin embargo sabemos que no hay an cién sin retorno de lo reprimido, esto es, no hay (il n'y a pas) como tal "lep in rido" rastreable en un tiempo y un espacio donde localizar el momento d r represión. Sólo su retorno que parte de una disociación original, de una difer nci), nos es cor sic 1 iado.

Puestos en guardia desde aquello que, de no ra imperfecta nable, denominamos "deconstrucción", todo discurso s toc Qevento sien pre sán anticipados por un antes que se subsume en un despa s y la ingober br awación-que porta consigo la marca de lo unheimlich $32-e_{0}$ la que ya, der de worigen como diferencia, habitaba el "efecto de retarc" 1 "represió " 6 Cómo pensar un presente reconstituido por el efecto de retardo sin que haya u a mgobernable alteración que se llamará Wiederholungszy ang, "compulsión la repetición"? Un tal impasse para el pensamiento es el dest o d psicoanáli is t y como lo conocemos desde la famosa carta ya meneiona da del 6/XII/1 39\% la impresión de las huellas mnémicas como Wahrnemun sszerouen se da en un acio-tiempo indeterminable y sólo es posible supone 1. impresión "or ginal a posteriori, après coup, gracias a una nueva inscriv, ión, una repeti $n$, yendo inmediatamente en un dato: si la génesis de la sis vificación se da sie ape a posteriori, con efecto de retardo, como diferencia V carmiento, nc se "ara "el" momento de la impresión original, no subsistirá el c igen puro de in esión. Siempre habrá en el origen una différance, un diferimiento en a to ae huellas mnémicas entrarán como significaciones en la cadena signif an nosteriori, por una sucesión de transcripciones. En esta différance habrá sien pre una pérdida, un resto irreductible por fuera de la significación, hors-signifié, que se plasmará en una repetición que nunca llegará a su destino.

\footnotetext{
31 Somos conscientes que la contraposición entre un "no ya natural" y el "no todavía discurso significante" puede resultar problemática, lo cual requeriría una mayor profundización que, por límites de tiempo, no podremos abarcar.

32 No es casual que la primera aparición del término Wiederholungszwang haga su aparición en el texto Das Unheimliche, donde todo aquello que estaba destinado a permanecer en lo oculto y clandestino, emerge a la luz. La aparición de la "compulsión a la repetición" que, lejos de permanecer oculta, se revela, se da en: cfr. Freud 1978, op. cit. (nota 17), p. 238.
} 
Hay algo que destrona al soberano "Lustprinzip", el que se había creído desde el comienzo de las tribulaciones analíticas como el rector del aparato anímico. Freud subsume a posteriori un imperio que se inscribirse en lo más íntimo de la naturaleza de las pulsiones: la compulsión a la repetición. ¿Pero podemos referirnos a la Wiederholungszwang como a un "principio"? La pregunta es capciosa y seductora porque ya vimos más arriba, en la cita de Derrida, que la compulsión a la repetición es indisociable de la pulsión de muerte ${ }^{33}$, de ese momento lógico en el que la pulsión retorna hacia aquello de lo cual surgió: lo inanimado. La pulsión es acéfala, sin ritmo identificable al no subsistir una variación en su emnuie: brota de un vacío al que retornará. Este origen diferido que supone la pu sić n de muerte como compulsión a la repetición, es lo que desbarata y "amenaza to da rincipialidad, toda primacía arcóntica, todo deseo de archivo"34. ¿Será este do ta '1e imiento en la intimidad del deseo de archivo a constituir el mal, la es ferm ed rd, la fiebre del archivo? El archivo como memoria y más alta constitución ael acontecimiento está, desde siempre, en pleno deshacimiento, roto, inco nplô to, porque y a spera-contaminando todo $\dot{\alpha} \rho \chi \dot{\eta}^{-}-$(la compulsión a) la rep tig

[...] bajo la forma de una pulsión de desu ccr n, la propia nul ion...e conservación, que podríamos asimismo denominar la $p$ ths on ae archivo. E to so que llamábamos hace poco, habida cuenta de esta contad cién interna, el ma de archivo. Ciertamente no habría deseo de archivo sin la fint d radical, sin la $\mathrm{p}_{\mathrm{s}} \mathrm{s}$ ilidad de un olvido que no se limita a la represión. Sobre 00 , y he aquí lo aás gra más allá o más acá de ese simple limite que se llama inı ad f finitud, no habn mal de archivo sin la amenaza de esa pulsión de muerte, de gr sion y de destruca án Âhora bien, esta amenaza es infinita, arrastra la lógica de a fil tud y los simp li nites fácticos, la estética trascendental, se podría decir las confrurones espacio-s mpurales de la conservación. Digamos más bien que abusa de llo y n abuso así bre a uimensión ético-política del problema. No hay un mal d a chr in-finitô, el mal de archive est $\mathrm{r}$ zando el mal radical. ${ }^{35}$

El 1 al de archivo de todo acontec qu po ta consigo una falta, una incompletud, una ruptura, una peligrosa lóg a s hlementaria corroída por un origen como différance, una pulsión que asume los intes de la muerte como "la impaciencia absoluta de un deseo de memoria" 36 .

33 Vid supra, p. 12.

34 Derrida 1995, op. cit., (nota 5), p. 20.

35 Ibidem, p. 27.

36 Ibidem, anexo. 
Para concluir aquello que no tiene término, la memoria y su repetición por y en el archivo, confiamos nuestro texto a las palabras del Poeta que trató de legar en la escritura la memoria del ser para el fundamento de lo imposible: el oficio de vivir, lo que solemos llamar "ética".

Ormai so che queste note di diario non contano per la loro scoperta esplicita, ma per lo spiraglio che aprono sul modo che inconsciam. ho di essere. Quel che dico non è vero, ma traduce -per il solo fatto che lo dico-il mio essere. 37

La escena y teatralidad de la escritura, las "notas de diaric" que soportan y posibilitan el decir, elemento archivador que esconde tanto or 10 revela, vehículo de la verdad como de la mentira, es asimismo la condición e sibilidad de todo acontecimiento que porta consigo el mal radical: una in obe nable disoci cón en la mismidad. El (mal de) archivo está siempre trabaj nl contra sí miš o mosibilitando todo acontecer.

Estos puntos finales son de gran inte, shespero que se n bi to de desarrollos ulteriores. También sería interesante, a poav de sugereren. y le alguna manera ya propuesto en el artículo de modo ma oir al, plantear la cuestión del archivo en el corpus lacaniano, del que Derrida su ocupa explíci ar 16 te si bien de modo problemático.

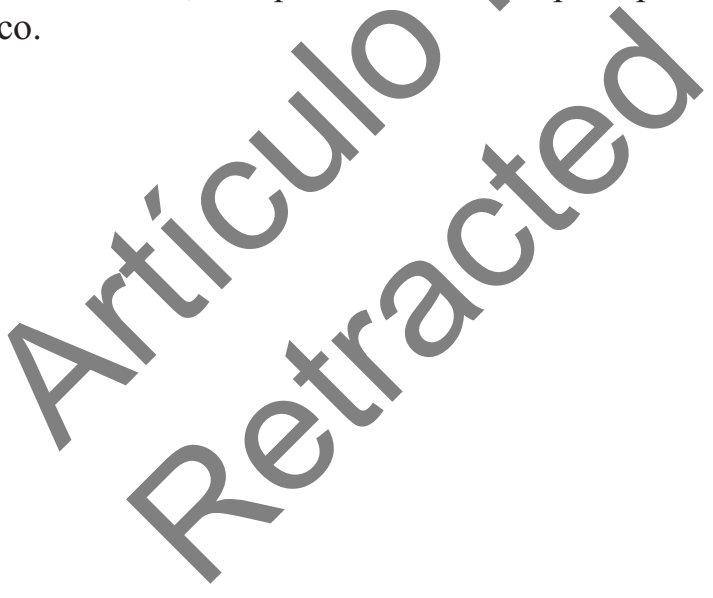

37 Pavese C., Il mestiere di vivere, Torino, Einaudi, 1992, pág. 322. "Ya sé que estas notas de diario no cuentan por su descubrimiento explícito, sino por la rendija que abren sobre el modo inconsciente que tengo de ser. Aquello que digo no es verdad, pero traiciona - por el sólo hecho de que lo digo- mi ser". Traducción nuestra. 